\title{
Chelating Ligand-Mediated Hydrothermal Synthesis of Samarium Orthovanadate with Decavanadate as Vanadium Source
}

\author{
Quanguo Li, Wenli Zuo, and Feng Li \\ College of Chemistry, Key Lab of Environment Friendly Chemistry and Application in Ministry of Education, \\ Xiangtan University, Xiangtan 411105, China \\ Correspondence should be addressed to Feng Li; fengli_xtu@hotmail.com
}

Received 28 April 2013; Accepted 21 July 2013

Academic Editors: E. R. Dockal and B. I. Kharisov

Copyright (c) 2013 Quanguo Li et al. This is an open access article distributed under the Creative Commons Attribution License, which permits unrestricted use, distribution, and reproduction in any medium, provided the original work is properly cited.

\begin{abstract}
A new ethylenediaminetetraacetic acid- (EDTA-) mediated hydrothermal route to prepare chrysanthemum-shaped samarium orthovanadate $\left(\mathrm{SmVO}_{4}\right)$ nanocrystals with decavanadate $\left(\mathrm{K}_{6} \mathrm{~V}_{10} \mathrm{O}_{28} \cdot 9 \mathrm{H}_{2} \mathrm{O}\right)$ as vanadium source has been developed. The present hydrothermal approach is simple and reproducible and employs a relatively mild reaction temperature. The EDTA, $\mathrm{pH}$ value, and temperature of the reaction systems play important roles in determining the morphologies and growth process of the $\mathrm{SmVO}_{4}$ products. The products have been characterized by X-ray diffraction (XRD), scanning electron microscopy (SEM), Fourier transform infrared spectroscopy (FT-IR), photoluminescence spectra (PL), and UV-Vis spectroscopy.
\end{abstract}

\section{Introduction}

Controllable synthesis of well-defined nanocrystals with uniform size and morphology such as wires, belts, tubes, cubes, and rods has attracted a worldwide interest due to their unique electronic, optical, and magnetic properties associated with the reduced dimensionality and their potential applications in nanotechnology [1-5]. As a consequence, various nanocrystals such as elemental semiconductors, IIVI and III-V semiconductors, metal oxides, metals, and inorganic salts on large scale have been prepared through all sorts of methods including templating direction, catalytic growth, electrochemistry, chemical vapor deposition, and solutionbased solvothermal or hydrothermal treatment [6-13]. In the synthesis of nanocrystals, there are two challenges now: (1) the morphology is restricted by the nature of crystals, which makes it difficult to control the morphology of the product; (2) the products always deviate from our research target. In recent reports, a special "capping reagent" has been used in the synthesis of nanocrystals. The "capping reagent" is used for tailoring the crystal growth and may also provide the possibility of breaking the nature of crystals, which may lead to more different morphologies and wider applications [14-16].
In recent years, $\mathrm{SmVO}_{4}$ nanocrystals have been widely studied as a prospective material because they exhibit unique properties and applications in many fields, such as catalysis [17], gas sensors [18], optical polarizers [19], lithium intercalated electrodes [20], thin film phosphors [21], laser host materials [22], solar cells [23], and unusual magnetic materials [24]. For example, $\mathrm{SmVO}_{4}$ nanocrystals exhibit high activity and selectivity as catalysts for many organic reactions, such as oxidative dehydrogenation of alkanes, olefins, ethylbenzene, and oxidation of hydrogen sulfide to elemental sulfur [25-35].

To date, most of the syntheses of $\mathrm{SmVO}_{4}$ nanocrystals adopt solid-state reaction and citrate method [36], which needs harsh conditions. For example, Tojo et al. synthesized $\mathrm{SmVO}_{4}$ crystals by milling the mixture of single oxides of $\mathrm{Sm}_{2} \mathrm{O}_{3}$ and $\mathrm{V}_{2} \mathrm{O}_{5}$ powders at $1000-1100^{\circ} \mathrm{C}$ [37]. Thus, it is expected to develop a low cost and convenient method for the synthesis of $\mathrm{SmVO}_{4}$ nanocrystals with well-defined sizes and shapes [38]. For this purpose, the hydrothermal method has been considered as one of the most convenient methods for the controlled synthesis of $\mathrm{SmVO}_{4}$ nanocrystals [39]. In the preparation of $\mathrm{SmVO}_{4}$, most syntheses adopted $\mathrm{VO}_{3}{ }^{-}$as the vanadium source, so it may be a good strategy for preparing 
$\mathrm{SmVO}_{4}$ with a new vanadium precursor [40]. Isopolyanions (e.g., decavanadate) may be a good candidate. In aqueous solutions, isopolyanions have versatile structures, and the structure of isopolyanions can be controlled by controlling the $\mathrm{pH}$ value. It means that we can obtain the target structure by adjusting the $\mathrm{pH}$ to a certain value, which is important for the preparation of aimed productions in the system of Sm-VO. To the best of our knowledge, there are no reports on the synthesis of $\mathrm{SmVO}_{4}$ with novel precursor decavanadate by the hydrothermal method yet.

In this paper, we synthesized chrysanthemum-shaped $\mathrm{SmVO}_{4}$ nanorods from the reaction of $\mathrm{K}_{6} \mathrm{~V}_{10} \mathrm{O}_{28} \cdot 9 \mathrm{H}_{2} \mathrm{O}$ and $\mathrm{SmCl}_{3} \cdot \mathrm{XH}_{2} \mathrm{O}$ precursors in the presence of capping reagent (EDTA) by hydrothermal method. The effects of the capping reagent, solution $\mathrm{pH}$ value, and reaction temperature on the shapes of the obtained $\mathrm{SmVO}_{4}$ nanocrystals have been studied. The possible mechanism for the formation of $\mathrm{SmVO}_{4}$ nanocrystals with various shapes is also proposed.

\section{Experimental Section}

2.1. Preparation of Decavanadate. The decavanadate $\left(\mathrm{K}_{6} \mathrm{~V}_{10} \mathrm{O}_{28} \cdot 9 \mathrm{H}_{2} \mathrm{O}\right)$ was prepared according to a described procedure [41].

2.2. Preparation of $\mathrm{SmVO}_{4}$ Products. $\mathrm{SmVO}_{4}$ products were prepared by hydrothermal method in the presence of capping reagent (EDTA). All reagents were analytical grade pure and used without further purification. In a typical procedure, $0.107 \mathrm{~g} \mathrm{~K}_{6} \mathrm{~V}_{10} \mathrm{O}_{28} \cdot 9 \mathrm{H}_{2} \mathrm{O}$ and 0.215 g ethylenediaminetetraacetic acid (EDTA) were dissolved into $30 \mathrm{~mL}$ distilled water, respectively. Stirring for $30 \mathrm{~min}, 0.073 \mathrm{~g} \mathrm{SmCl} \cdot \mathrm{XH}_{2} \mathrm{O}$ was dissolved into $20 \mathrm{~mL}$ distilled water. $\mathrm{SmCl}_{3} \cdot \mathrm{XH}_{2} \mathrm{O}$ solution was added into $\mathrm{K}_{6} \mathrm{~V}_{10} \mathrm{O}_{28} \cdot 9 \mathrm{H}_{2} \mathrm{O}$ solution. After stirring for $10 \mathrm{~min}$, EDTA solution was added into the solution, and $20 \mathrm{~min}$ later, sodium hydroxide solution $(1 \mathrm{~mol} / \mathrm{L})$ was added dropwise into the solution to adjust the $\mathrm{pH}$ to the designed range (from 4 to 10). The resulting suspension was transferred into a $100 \mathrm{~mL}$ Teflon-lined stainless steel autoclave and sealed tightly. Hydrothermal synthesis was carried out at $140 \sim 180^{\circ} \mathrm{C}$ for $48 \mathrm{~h}$ in an electric oven without shaking or stirring. After cooling to room temperature naturally, the precipitates were collected, washed with distilled water and absolute ethanol for several times, and then dried in a vacuum oven at about $60^{\circ} \mathrm{C}$ for $10 \mathrm{~h}$.

2.3. Characterization of $\mathrm{SmVO}_{4}$ Products. The $\mathrm{pH}$ values of the solution were measured by Leici $\mathrm{pH}$ Meter of Shanghai Precision and Scientific Instrument Corporation China. The phase purity and crystal structure of the obtained products were examined by X-ray diffraction (XRD) using a MiniFlex2 goniometer, employing a scanning rate of $0.02^{\circ} \mathrm{s}^{-1}$ in the $2 \theta$ range of $5^{\circ}-70^{\circ}$. The operation voltage and current were maintained at $30 \mathrm{kV}$ and $15 \mathrm{~mA}$, respectively. The size distribution and morphology of the products were analyzed by scanning electron microscopy (SEM) (JSM-6610LV). The $\mathrm{UV}$-Vis spectra of the as-synthesized $\mathrm{SmVO}_{4}$ nanocrystals were recorded on a Lambda 25 spectrometer. Fourier transform infrared spectroscopic (FTIR) analysis was carried out in the region of $4000-400 \mathrm{~cm}^{-1}$ by a PerkineElmer spectrometer instrument (pressed $\mathrm{KBr}$ disks). Room temperature photoluminescence (PL) spectra were recorded on a Hitachi 850 fluorescence spectrometer with Xe lamp as the excitation source at $25^{\circ} \mathrm{C}$.

\section{Results and Discussion}

3.1. Structural Analysis. The phase identification of all the products was performed by XRD. Figure 1(a) shows the XRD patterns of the products obtained via hydrothermal method with deferent $\mathrm{pH}$ values. The products synthesized with $\mathrm{pH}$ values of $4,6,8$, and 10 show similar patterns, which can be indexed as the tetragonal zircon phase of $\mathrm{SmVO}_{4}$ with lattice contents of $a=b=7.265 \AA$ and $c=6.389 \AA$, and are in good agreement with the standard values for the tetragonal phase $\mathrm{SmVO}_{4}$ (Fm3hm, JCPDS no. 17-0876) [42]. No XRD peaks correspond to single metal oxides of $\mathrm{V}_{2} \mathrm{O}_{5}$ [43], and $\mathrm{Sm}_{2} \mathrm{O}_{3}$ [44] were detected, indicating that the pure $\mathrm{SmVO}_{4}$ nanocrystals with tetragonal zircon-type structure can be obtained by this method. From Figure 1(a), we observed that the crystallinity of obtained products increased with the increasing of the $\mathrm{pH}$ value of the solution, when we kept the reaction temperature at $180^{\circ} \mathrm{C}$. Obviously, the $\mathrm{pH}$ value of the solution plays an important role in the preparation of pure $\mathrm{SmVO}_{4}$ by hydrothermal method.

To investigate the effect of temperature on the crystallinity, $\mathrm{SmVO}_{4}$ was prepared at different reaction temperatures. When the reaction temperature was $140^{\circ} \mathrm{C}$, the crystallinity of the as-prepared product was low, and few peaks can be observed. Therefore, a higher temperature may help the formation of the thermodynamically stable, well-crystallized, and uniform products. It is very clear that the crystallinity of the obtained products increases with the increasing of the reaction temperature at $\mathrm{pH}=10$ (Figure $1(\mathrm{~b})$ ). Thus, we conclude that the solution $\mathrm{pH}$ value and temperature of the reaction systems play important roles in determining the crystallinity of the $\mathrm{SmVO}_{4}$ nanocrystals. Moreover, it can also be concluded that the formation of the pure tetragonal $\mathrm{SmVO}_{4}$ phase results in complete reaction of the $1: 1$ ratio of $\mathrm{Sm}^{3+}$ cation and $\mathrm{VO}_{4}{ }^{3-}$ anion monomers in the bulk solution during the synthesis.

To further confirm the formation of the $\mathrm{SmVO}_{4}$, Fourier transform infrared (FT-IR) spectroscopy was performed (Figure 2). The weak band at $447 \mathrm{~cm}^{-1}$ is due to the $v_{4}$ antisymmetric deformation, and the strong absorption band at $803 \mathrm{~cm}^{-1}$ corresponds to the $v_{3}$ vibrational mode that belongs to antisymmetric stretching of $\mathrm{VO}_{4}$ tetrahedron [45]. It shows that the crystalline phase of $\mathrm{SmVO}_{4}$ formed in the asprepared product. The absorption band located at $3430 \mathrm{~cm}^{-1}$ and $1643 \mathrm{~cm}^{-1}$ can be ascribed to the $\mathrm{O}-\mathrm{H}$ stretching and bending vibrations of free water molecules adsorbed by products from the aqueous solution.

3.2. Morphology Control. The morphology and structure of the as-prepared $\mathrm{SmVO}_{4}$ nanocrystals were further characterized by SEM. Figure 3 shows the typical SEM images of the $\mathrm{SmVO}_{4}$ nanocrystals at the reaction temperature of $180^{\circ} \mathrm{C}$. When the $\mathrm{pH}$ is lower than 4 , the obtained products take 


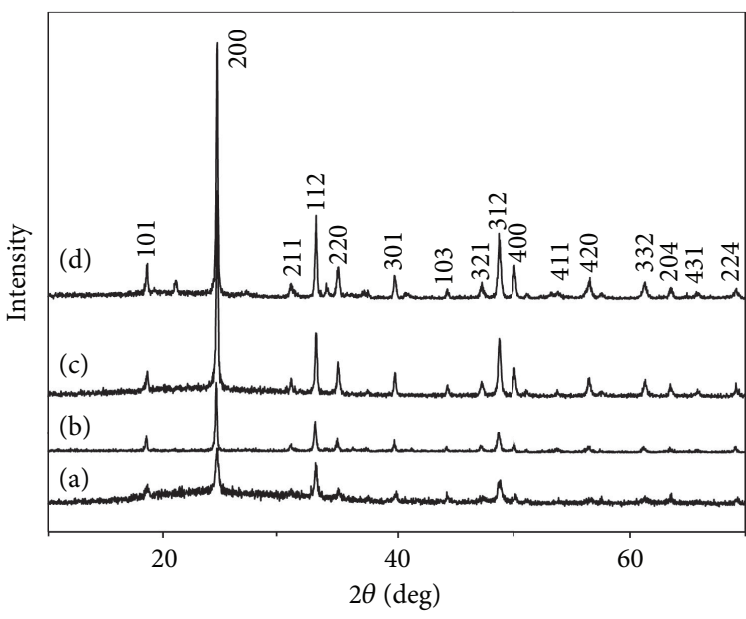

(A)

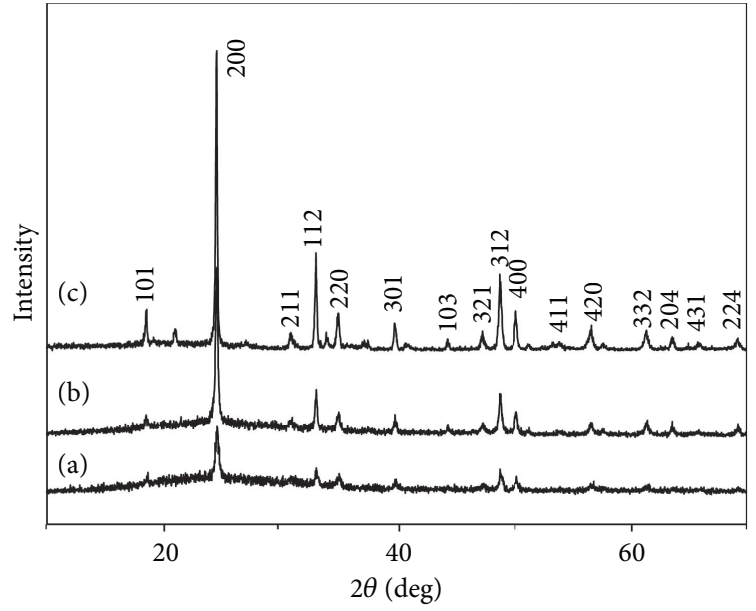

(B)

FIGURE 1: X-ray diffraction patterns of $\mathrm{SmVO}_{4}$ nanocrystals obtained (A) under $180^{\circ} \mathrm{C}$, with different pH values: (a) EDTA, pH = 4; (b) EDTA, $\mathrm{pH}=6$; (c) EDTA, $\mathrm{pH}=8$; (d) EDTA, $\mathrm{pH}=10$, and (B) under $\mathrm{pH}=10$, with different temperatures: (a) EDTA, $140^{\circ} \mathrm{C}$; (b) EDTA, $160^{\circ} \mathrm{C}$; (c) EDTA, $180^{\circ} \mathrm{C}$.

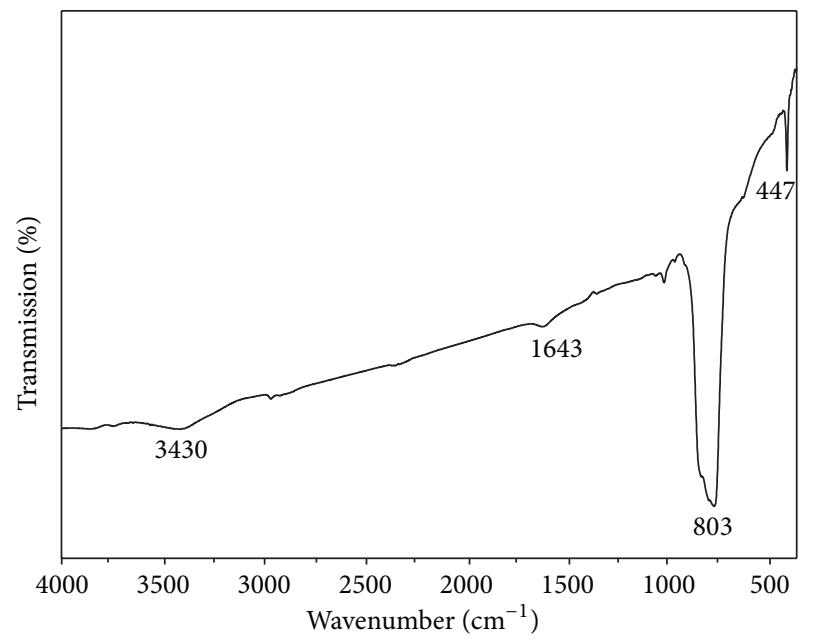

FIGURE 2: The FT-IR spectrum of $\mathrm{SmVO}_{4}$ nanocrystals synthesized under $180^{\circ} \mathrm{C}, \mathrm{EDTA}, \mathrm{pH}=10$.

on a dumbbell-shaped structure (Figure 3(a)). It is noted that the centers of several dumbbells are connected together. When the $\mathrm{pH}$ is higher than 8 , the obtained products are chrysanthemum shaped with a high density of nanorods (Figure 3(d)). When the $\mathrm{pH}$ values are higher than 4 and lower than 8 , the chrysanthemum-shaped structure appears with a lower ratio. As shown in Figure 3(b), we can observe that the amount of nanorods is relatively rare. With the increasing of the $\mathrm{pH}$ value, the density and aspect ratio of those nanorods are improved (Figures 3(c) and 3(d)). These results indicate that $\mathrm{pH}$ value is a key factor in the formation of the chrysanthemum-shaped structure of $\mathrm{SmVO}_{4}$ nanocrystals.

In order to better understand the formation and evolution of $\mathrm{SmVO}_{4}$ nanostructures with the reaction temperature, reactions at $140^{\circ} \mathrm{C}$ and $160^{\circ} \mathrm{C}$ with the $\mathrm{pH}$ value of 10 were carried out. The SEM image of the product obtained from hydrothermal reactions at $140^{\circ} \mathrm{C}$ was shown in Figure 4(a). It is clearly shown that the as-synthesized products are composed of nanorods with inhomogeneous size distribution. When the reaction temperature was increased to $160^{\circ} \mathrm{C}$, a large number of nanorods formed (Figure 4(b)). Some of them arranged regularly, and the density is higher than that in Figure 4(a). However, when the reaction temperature was increased to $180^{\circ} \mathrm{C}$, the chrysanthemum-shaped structure of nanorods appeared, and the density and aspect ratio were further improved (Figure 4(c)). These results indicate that the reaction temperature has an important effect on the formation of chrysanthemum-shaped $\mathrm{SmVO}_{4}$ nanocrystals.

3.3. Formation Mechanism. Without EDTA in the reaction system, the tetragonal $\mathrm{SmVO}_{4}$ precipitates are aggregates of highly nanorods with inhomogeneous size distribution, and those nanorods were arranged inconstantly (Figure 3(e)). When EDTA was introduced into the reaction system, $\mathrm{SmVO}_{4}$ products with a high aspect ratio and density can be obtained, if the $\mathrm{pH}$ value and the reaction temperature are well controlled. These initial products can be mediated by the ligands adsorbed on the surface of crystals, and they will serve as seeds for the growth of highly anisotropic nanostructures in the solution-solid process via the dissolution and crystallization mechanisms [46, 47]. The reason of introducing EDTA is based on its chelating and capping effects, which will influence the growth rate of different facets distinguishingly. Once the EDTA is dissociated from the $\mathrm{Sm}^{3+}$ ions, it will bind to the specific surface of the precipitated $\mathrm{SmVO}_{4}$, which directly affects the facet growth and crystallinity of the nanocrystals [48]. The reason that the $\mathrm{pH}$ values influence the morphology of $\mathrm{SmVO}_{4}$ nanocrystals can be easily understood by taking the following considerations. When the $\mathrm{pH}$ value is lower than $4, \mathrm{~V}_{10} \mathrm{O}_{28}{ }^{6-}$ is stable, and the product is a 


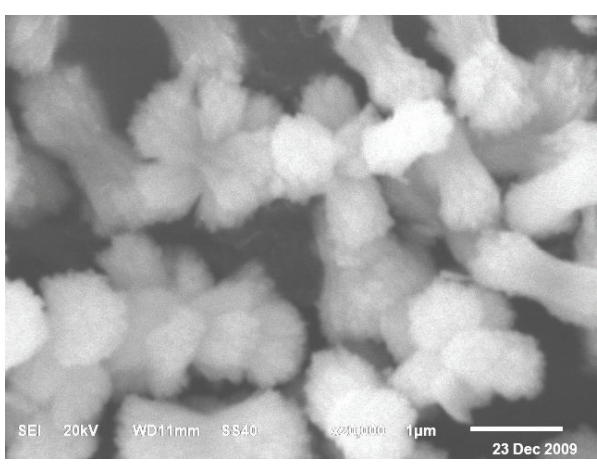

(a)

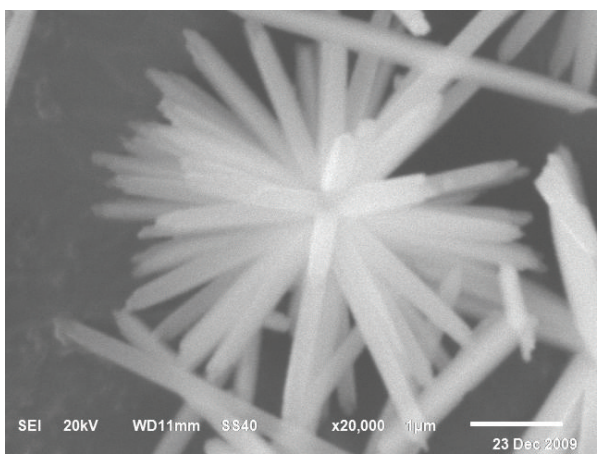

(c)

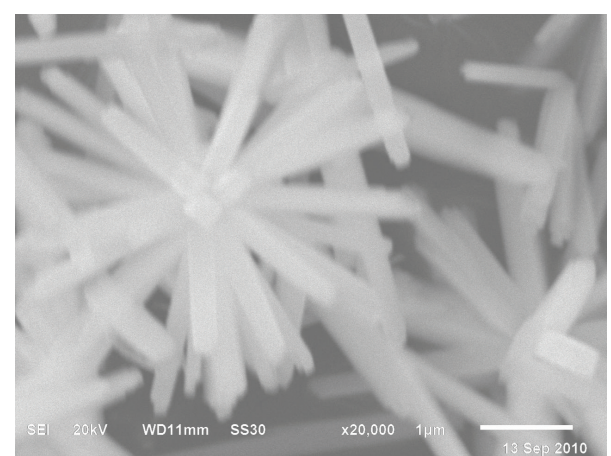

(b)

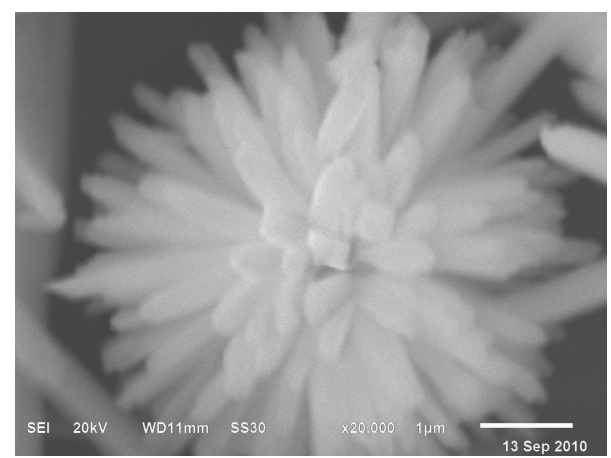

(d)

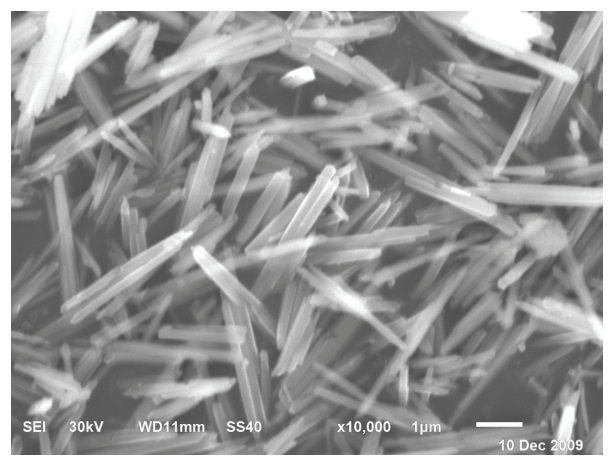

(e)

FIGURE 3: SEM images of $\mathrm{SmVO}_{4}$ nanocrystals synthesized under $180^{\circ} \mathrm{C}$, with different reaction conditions: (a) EDTA, $\mathrm{pH}=4$; (b) EDTA, $\mathrm{pH}$ = 6; (c) EDTA, $\mathrm{pH}=8$; (d) EDTA, $\mathrm{pH}=10$; (e) absence of EDTA, $\mathrm{pH}=6$.

dumbbell-shaped framework [49]. Since $\mathrm{Sm}^{3+}$ exists near the surrounding of anion framework, we suppose that the nucleation happens at the interface. When the framework is broken due to the increasing of the $\mathrm{pH}$ value of the reaction system, polyorthovanadate anion turns into $\mathrm{VO}_{4}{ }^{3-}$ ions and forms chrysanthemum-shaped structure. When $\mathrm{pH}$ is kept at $10, \mathrm{VO}_{4}{ }^{3-}$ anion is the main form of orthovanadate, so no dumbbell shapes are observed. When the $\mathrm{pH}$ of the reaction system is kept at lower value, the aspect ratio of the chrysanthemum-shaped nanostructure of $\mathrm{SmVO}_{4}$ is reduced because of the weakened chelation and capping abilities of EDTA. Moreover, the heat treatment temperature also plays important roles in determining the shape of the products. The strong ligand (EDTA) plays two roles. It is not only required to form a stable complex with $\mathrm{Sm}^{3+}$ but also acts as a capping reagent binding to the surface of crystals, which directly affects the facet growth and crystallinity of the nanocrystals. Therefore, we can control the aspect ratio and the density of $\mathrm{SmVO}_{4}$ nanocrystals by adjusting the $\mathrm{pH}$ value and the reaction temperature when EDTA is introduced.

3.4. UV-Vis Spectroscopy and Photoluminescence Properties of $\mathrm{SmVO}_{4}$ Nanocrystals. UV-Vis spectroscopy has been used for characterizing the optical property of the $\mathrm{SmVO}_{4}$ nanocrystals. Examples for the UV-Vis absorption spectra experiments were prepared by dispersing the as-prepared $\mathrm{SmVO}_{4}$ nanocrystals in ethanol with sonication bath for $30 \mathrm{~min}$ to form clear solutions. Figure 5 gives the UV-Vis absorption spectra of the $\mathrm{SmVO}_{4}$ nanocrystals obtained at different $\mathrm{pH}$ values of 4, 6, 8, and 10. As shown in Figure 5, the absorption 


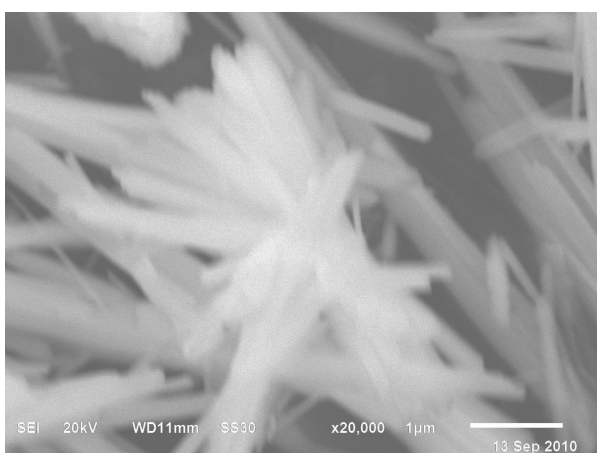

(a)

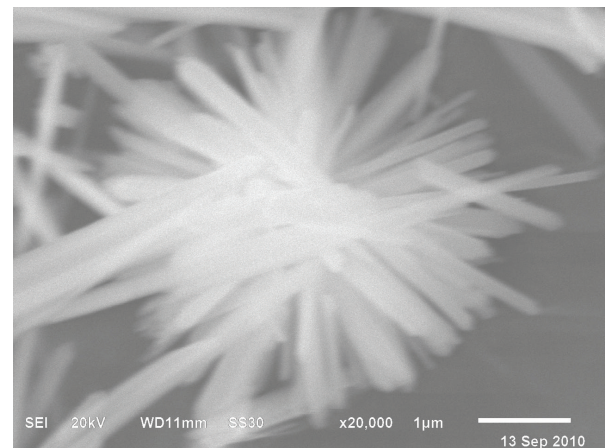

(b)

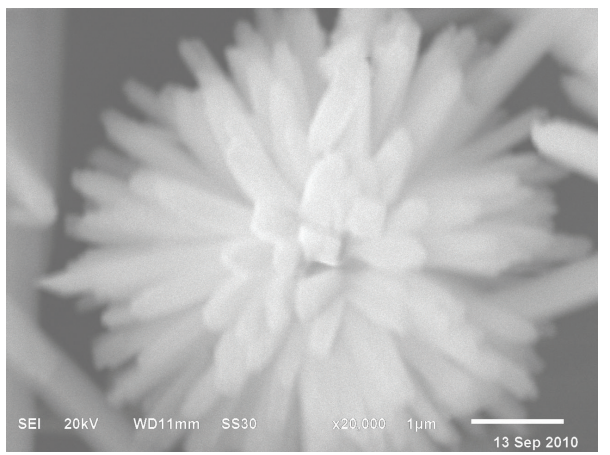

(c)

FIGURE 4: SEM images of the $\mathrm{SmVO}_{4}$ nanocrystals synthesized under $\mathrm{pH}=9.7$, with different reaction temperatures: (a) EDTA, $140^{\circ} \mathrm{C}$; (b) EDTA, $160^{\circ} \mathrm{C}$; (c) EDTA, $180^{\circ} \mathrm{C}$.

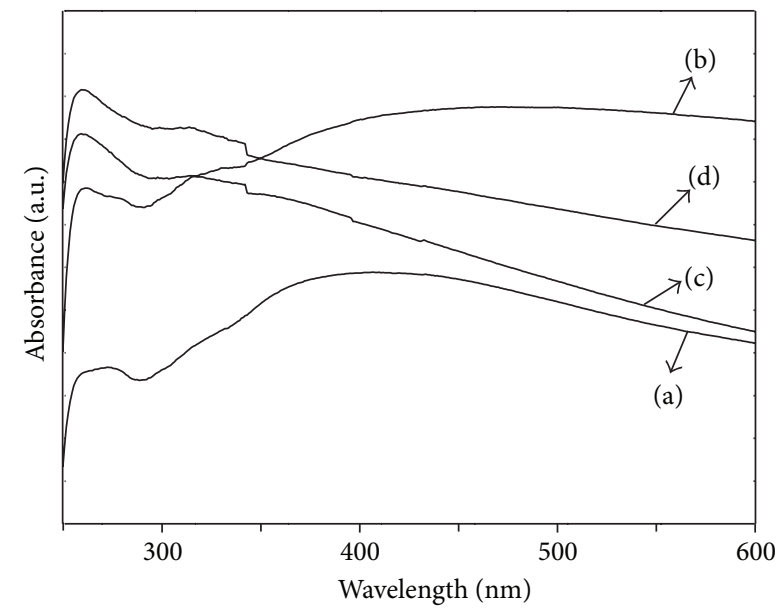

FIGURE 5: UV-Vis spectra of the as-synthesized $\mathrm{SmVO}_{4}$ nanocrystals under $180^{\circ} \mathrm{C}$, with different $\mathrm{pH}$ values: (a) EDTA, $\mathrm{pH}=4$; (b) EDTA, $\mathrm{pH}=6$; (c) EDTA, $\mathrm{pH}=8$; (d) EDTA, $\mathrm{pH}=10$.

peaks of the products at about $250 \mathrm{~nm}$ are attributed to the charge transfer from the oxygen ligands to the central vanadium atom inside the $\mathrm{VO}_{4}{ }^{3-}$ groups in the samarium orthovanadate [50].

The room temperature photoluminescence spectrum of the as-synthesized $\mathrm{SmVO}_{4}$ with the excitation of $288 \mathrm{~nm}$ was shown in Figure 6. It shows one strong and broad red

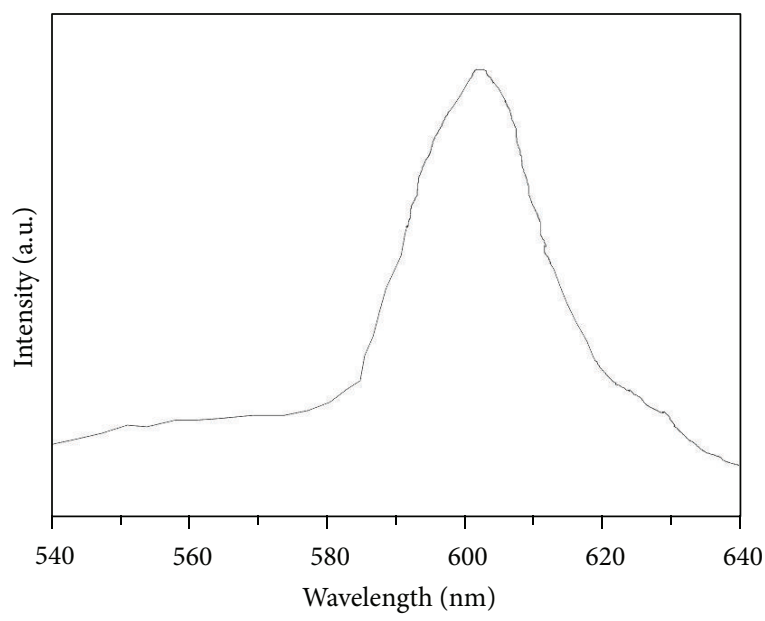

FIGURE 6: Room temperature photoluminescence spectra of tetragonal $\mathrm{SmVO}_{4}$ nanocrystals obtained after the hydrothermal treatment under $180^{\circ} \mathrm{C}$, EDTA, $\mathrm{pH}=10$.

emission at $605 \mathrm{~nm}$, which is a characteristic transition from ${ }^{4} \mathrm{G}_{5 / 2}$ to ${ }^{6} \mathrm{H}_{7 / 2}$ states of $\mathrm{Sm}$ (III) [50].

\section{Conclusions}

In summary, chrysanthemum-shaped $\mathrm{SmVO}_{4}$ nanorods have been successfully prepared with a novel precursor decavanadate in the presence of EDTA. It was found that the $\mathrm{pH}$ value, 
the reaction temperature, and the introduction of EDTA play key roles in the morphology evolution of the products. In addition, a possible growth mechanism of $\mathrm{SmVO}_{4}$ with the morphology of chrysanthemum was discussed. Due to the simplicity of this system and the efficient control over the morphology, we suppose that this method may have wide applications in exploring the crystal growth process and provide guidance for the morphology controllable synthesis of other functional inorganic materials.

\section{Acknowledgments}

The authors acknowledge the financial support of Scientific Research Fund of Hunan Provincial Education Department, China (11C1205), and Provincial Natural Science Foundation of Hunan, China (13JJ6041).

\section{References}

[1] J. T. Hu, T. W. Odom, and C. M. Lieber, "Chemistry and physics in one dimension: synthesis and properties of nanowires and nanotubes," Accounts of Chemical Research, vol. 32, no. 5, pp. 435-445, 1999.

[2] Y. Xia, P. Yang, Y. Sun et al., "One-dimensional nanostructures: synthesis, characterization, and applications," Advanced Materials, vol. 15, no. 5, pp. 353-389, 2003.

[3] Y. Y. Wu, H. Q. Yan, M. Huang, B. Messer, J. H. Song, and P. D. Yang, "Inorganic semiconductor nanowires: rational growth, assembly, and novel properties," Chemistry, vol. 8, pp. 12601268, 2002.

[4] G. R. Patzke, F. Krumeich, and R. Nesper, "Oxidic nanotubes and nanorods-anisotropic modules for a future nanotechnology," Angewandte Chemie, vol. 41, no. 14, pp. 2446-2461, 2002.

[5] D. L. Klein, R. Rotht, A. K. L. Lim, A. P. Alivisatosti, and P. L. McEuen, "A single-electron transistor made from a cadmium selenide nanocrystal," Nature, vol. 389, no. 6652, pp. 699-701, 1997.

[6] H. W. Zhu, C. L. Xu, D. H. Wu, B. Q. Wei, R. Vajtai, and P. M. Ajayan, "Direct synthesis of long single-walled carbon nanotube strands," Science, vol. 296, no. 5569, pp. 884-886, 2002.

[7] Y. Feldman, E. Wasserman, D. J. Srolovitz, and R. Tenne, "Highrate, gas-phase growth of $\mathrm{MoS}_{2}$ nested inorganic fullerenes and nanotubes," Science, vol. 267, no. 5195, pp. 222-225, 1995.

[8] Y. D. Li, X. L. Li, Z. X. Deng et al., "From surfactant-Inorganic mesostructures to tungsten nanowires," Angewandte Chemie, vol. 41, pp. 333-335, 2002.

[9] X. Duan, Y. Huang, R. Agarwal, and C. M. Lieber, "Singlenanowire elecctrically driven lasers," Nature, vol. 421, no. 6920, pp. 241-245, 2003.

[10] J. Zhang, L. Sun, J. Yin, H. Su, C. Liao, and C. Yan, "Control of $\mathrm{ZnO}$ morphology via a simple solution route," Chemistry of Materials, vol. 14, no. 10, pp. 4172-4177, 2002.

[11] D. F. Zhang, L. D. Sun, J. L. Yin, and C. H. Yan, "Low-temperature fabrication of highly crystalline $\mathrm{SnO}_{2}$ nanorods," $\mathrm{Ad}$ vanced Materials, vol. 15, no. 12, pp. 1022-1025, 2003.

[12] R. Z. Ma, Y. Bando, and T. Sato, "Controlled synthesis of BN nanotubes, nanobamboos, and nanocables," Advanced Materials, vol. 14, pp. 366-368, 2002.

[13] M. Nath and C. N. R. Rao, "Nanotubes of group 4 metal disulfides," Angewandte Chemie, vol. 41, pp. 3451-3454, 2002.
[14] Y. D. Yin, Y. Lu, Y. G. Sun, and Y. N. Xia, "Silver nanowires can be directly coated with amorphous silica to generate wellcontrolled coaxial nanocables of silver/silica," Nano Letters, vol. 2, pp. 427-430, 2002.

[15] X. Peng, L. Manna, W. Yang et al., "Shape control of CdSe nanocrystals," Nature, vol. 404, no. 6773, pp. 59-61, 2000.

[16] L. Manna, E. C. Scher, and A. P. Alivisatos, "Synthesis of soluble and processable rod-, arrow-, teardrop-, and tetrapod-shaped CdSe nanocrystals," Journal of the American Chemical Society, vol. 122, no. 51, pp. 12700-12706, 2000.

[17] C. T. Au and W. D. Zhang, "Oxidative dehydrogenation of propane over rare-earthorthovanadates," Journal of the Chemical Society, Faraday Transactions, vol. 93, no. 6, pp. 1195-1204, 1997.

[18] E. V. Tsipis, M. V. Patrakeev, V. V. Kharton, N. P. Vyshatko, and J. R. Frade, "Ionic and p-type electronic transport in zircon-type $\mathrm{Ce}_{1-x} \mathrm{~A}_{x} \mathrm{VO}_{4 \pm \delta}(\mathrm{A}=\mathrm{Ca}, \mathrm{Sr})$," Journal of Materials Chemistry, vol. 12, no. 12, pp. 3738-3745, 2002.

[19] F. Chen, X. Wang, S. Li et al., "Low-loss optical planar waveguides in $\mathrm{YVO}_{4}$ produced by silicon ion implantation at low doses," Journal of Applied Physics, vol. 94, pp. 4708-4710, 2003.

[20] G. Picardi, F. Varsano, F. Decker, U. Opara-Krasovec, A. Surca, and B. Orel, "Electrochemical characterization of optically passive $\mathrm{CeVO}_{4}$ counterelectrodes," Electrochimica Acta, vol. 44, no. 18, pp. 3157-3164, 1999.

[21] M. Yu, J. Lin, and S. B. Wang, "Effects of $x$ and $\mathrm{R}^{3+}$ on the luminescent properties of $\mathrm{Eu}^{3+}$ in nanocrystalline $\mathrm{YV}_{x} \mathrm{P}_{1-x} \mathrm{O}_{4}: \mathrm{Eu}^{3+}$ and $\mathrm{RVO}_{4}: \mathrm{Eu}^{3+}$ thin-film phosphors ", Applied Physics A, vol. 80, pp. 353-360, 2005.

[22] R. A. Fields, M. Birnbaum, and C. L. Fincher, "Highly efficient $\mathrm{Nd}: \mathrm{YVO}_{4}$ diode-laser end-pumped laser," Applied Physics Letters, vol. 51, no. 23, pp. 1885-1856, 1987.

[23] J. F. Liu, Q. H. Yao, and Y. D. Li, "Effects of downconversion luminescent film in dye-sensitized solar cells," Applied Physics Letters, vol. 88, pp. 173119-173121, 2006.

[24] K. Gaur and H. B. Lal, "Unusual magnetic behaviour of heavy rare earth vanadates at higher temperature," Journal of Materials Science Letters, vol. 2, no. 12, pp. 744-746, 1983.

[25] J. W. Stouwdam, M. Raudsepp, and F. C. J. M. van Veggel, “Colloidal nanoparticles of $\mathrm{Ln}^{3+}$-doped $\mathrm{LaVO}_{4}$ : energy transfer to visible- and near-infrared-emitting lanthanide ions," Langmuir, vol. 21, no. 15, pp. 7003-7008, 2005.

[26] J. Matta, D. Courcot, E. Abi-Aad, and A. Aboukaïs, "Identification of vanadium oxide species and trapped single electrons in interaction with the $\mathrm{CeVO}_{4}$ phase in vanadium-cerium oxide systems.51V MAS NMR, EPR, Raman, and thermal analysis studies," Chemistry of Materials, vol. 14, no. 10, pp. 4118-4125, 2002.

[27] C. T. Au, W. D. Zhang, and H. L. Wan, "Preparation and characterization of rare earth orthovanadates for propane oxidative dehydrogenation," Catalysis Letters, vol. 37, no. 3-4, pp. 241-246, 1996.

[28] S. Sugunan and N. K. Renuka, "Oxidative dehydrogenation of ethylbenzene over $\mathrm{Sm}_{2} \mathrm{O}_{3}-\mathrm{V}_{2} \mathrm{O}_{5}$ system," Bulletin of the Chemical Society of Japan, vol. 75, pp. 463-471, 2002.

[29] E. A. Mamedov and V. C. Corberfin, "Oxidative dehydrogenation of lower alkanes on vanadium oxide-based catalysts. The present state of the art and outlooks," Applied Catalysis A, vol. 127, pp. 1-40, 1995.

[30] B. P. Barbero and L. E. Cadus, "Vanadium species: Sm-V-O catalytic system for oxidative dehydrogenation of propane," Applied Catalysis A, vol. 244, no. 2, pp. 235-249, 2003. 
[31] K. T. Li and Z. H. Chi, "Selective oxidation of hydrogen sulfide on rare earth orthovanadates and magnesium vanadates," Applied Catalysis A, vol. 206, pp. 197-203, 2001.

[32] B. P. Barbero and L. E. Cadus, "Evaluation and characterization of $\mathrm{Sm}-\mathrm{V}-\mathrm{O}$ catalytic system for propane oxydehydrogenation: $\mathrm{Sm}_{2} \mathrm{O}_{3}$-impregnated $\mathrm{V}_{2} \mathrm{O}_{5}$ catalysts," Applied Catalysis A, vol. 234, pp. 245-258, 2002.

[33] I. Lee, R. Morales, M. A. Albiter, and F. Zaera, "Synthesis of heterogeneous catalysts with well shaped platinum particles to control reaction selectivity," Proceedings of the National Academy of Sciences of the United States of America, vol. 105, no. 40, pp. 15241-15246, 2008.

[34] F. Tao, M. E. Grass, Y. Zhang et al., "Reaction-driven restructuring of Rh-Pd and Pt-Pd core-shell nanoparticles," Science, vol. 322, no. 5903, pp. 932-934, 2008.

[35] H. Friedrich, P. E. De Jongh, A. J. Verkleij, and K. P. De Jong, "Electron tomography for heterogeneous catalysts and related nanostructured materials," Chemical Reviews, vol. 109, no. 5, pp. 1613-1629, 2009.

[36] P. Courty, H. Ajot, C. Marcilly, and B. Delmon, "Oxydes mixtes ou en solution solide sous forme très divisée obtenus par décomposition thermique de précurseurs amorphes," Powder Technology, vol. 7, no. 1, pp. 21-38, 1973.

[37] T. Tojo, Q. Zhang, and F. J. Saito, "Mechanochemical synthesis of rare earth orthovanadates from $\mathrm{R}_{2} \mathrm{O}_{3}(\mathrm{R}=$ rare earth elements) and $\mathrm{V}_{2} \mathrm{O}_{5}$ powders," Journal of Alloys and Compounds, vol. 427, pp. 219-222, 2007.

[38] J. Liu, W. Chen, X. Liu, K. Zhou, and Y. Li, "Au/LaVO ${ }_{4}$ Nanocomposite: preparation, characterization, and catalytic activity for CO oxidation," Nano Research, vol. 1, pp. 46-55, 2008.

[39] S. Mahapatra and A. Ramanan, "Hydrothermal synthesis and structural study of lanthanide orthovanadates, $\mathrm{LnVO}_{4}(\mathrm{Ln}=$ Sm, Gd, Dy and Ho)," Journal of Alloys and Compounds, vol. 395, no. 1-2, pp. 149-153, 2005.

[40] T. Nguyen, C. Dinh, D. Nguyen, and T. Do, "A novel approach for monodisperse samarium orthovanadate nanocrystals: controlled synthesis and characterization," Journal of Physical Chemistry C, vol. 113, no. 43, pp. 18584-18595, 2009.

[41] J. N. Xu, G. Y. Yang, H. R. Sun, and T. G. Wang, "Synthesis and crystal structure of $\mathrm{K}_{6} \mathrm{~V}_{10} \mathrm{O}_{28} \cdot 9 \mathrm{H}_{2} \mathrm{O}$," Chemical Research and Application, vol. 9, pp. 576-581, 1997.

[42] W. Fana, W. Zhao, L. You et al., "A simple method to synthesize single-crystalline lanthanide orthovanadate nanorods," Journal of Solid State Chemistry, vol. 177, pp. 4399-4403, 2004.

[43] T. Nguyen and T. Do, "Solvo-hydrothermal approach for the shape-selective synthesis of vanadium oxide nanocrystals and their characterization," Langmuir, vol. 25, no. 9, pp. 5322-5332, 2009.

[44] T. Nguyen, D. Mrabet, and T. Do, "Controlled self-assembly of $\mathrm{Sm}_{2} \mathrm{O}_{3}$ nanoparticles into nanorods: simple and large scale synthesis using bulk $\mathrm{Sm}_{2} \mathrm{O}_{3}$ powders," Journal of Physical Chemistry C, vol. 112, no. 39, pp. 15226-15235, 2008.

[45] W. Chen, L. Q. Mai, J. F. Peng, Q. Xu, and Q. Y. Zhu, "FTIR study of vanadium oxide nanotubes from lamellar structure," Journal of Materials Science, vol. 39, no. 7, pp. 2625-2627, 2004.

[46] B. Gates, Y. Yin, and Y. Xia, "A solution-phase approach to the synthesis of uniform nanowires of crystalline selenium with lateral dimensions in the range of $10-30 \mathrm{~nm}$," Journal of the American Chemical Society, vol. 122, no. 50, pp. 12582-12583, 2000.

[47] J. Lu, Y. Xie, F. Xu, and L. Y. Zhu, "Study of the dissolution behavior of selenium and tellurium in different solvents-a novel route to Se, Te tubular bulk single crystals," Journal of Materials Chemistry, vol. 12, pp. 2755-2761, 2002.

[48] T. N. Thomas, T. A. Land, J. J. DeYoreo, and W. H. Casey, "In situ atomic force microscopy investigation of the 100 face of $\mathrm{KH}$ $2 \mathrm{PO}_{4}$ in the presence of $\mathrm{Fe}(\mathrm{III}), \mathrm{Al}(\mathrm{III})$, and $\mathrm{Cr}(\mathrm{III})$," Langmuir, vol. 20, no. 18, pp. 7643-7652, 2004.

[49] N. N. Greenwood and A. A. Earnshaw, Eds., Chemistry of the Elements, Butterworth-Heinemann, Oxford, UK, 2nd edition, 1998.

[50] R. K. Selvan, A. Gedanken, P. Anilkumar, G. Manikandan, and C. Karunakaran, "Synthesis and characterization of rare earth orthovanadate $\left(\mathrm{RVO}_{4} ; \mathrm{R}=\mathrm{La}, \mathrm{Ce}, \mathrm{Nd}, \mathrm{Sm}, \mathrm{Eu} \& \mathrm{Gd}\right)$ nanorods/nanocrystals/nanospindles by a facile sonochemical method and their catalytic properties," Journal of Cluster Science, vol. 20, no. 2, pp. 291-305, 2009. 

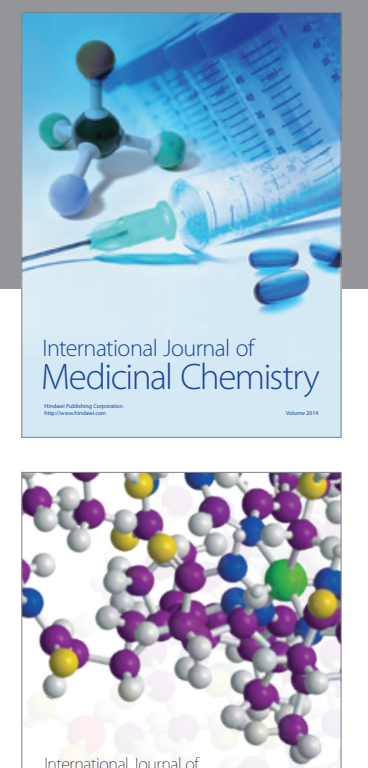

\section{Carbohydrate} Chemistry

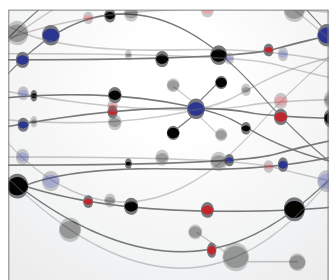

The Scientific World Journal
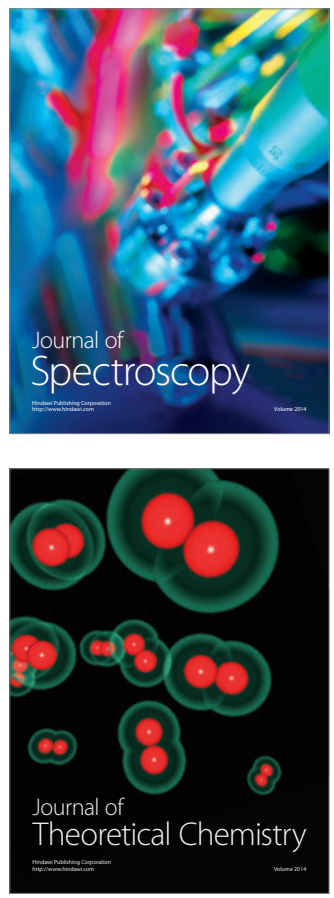
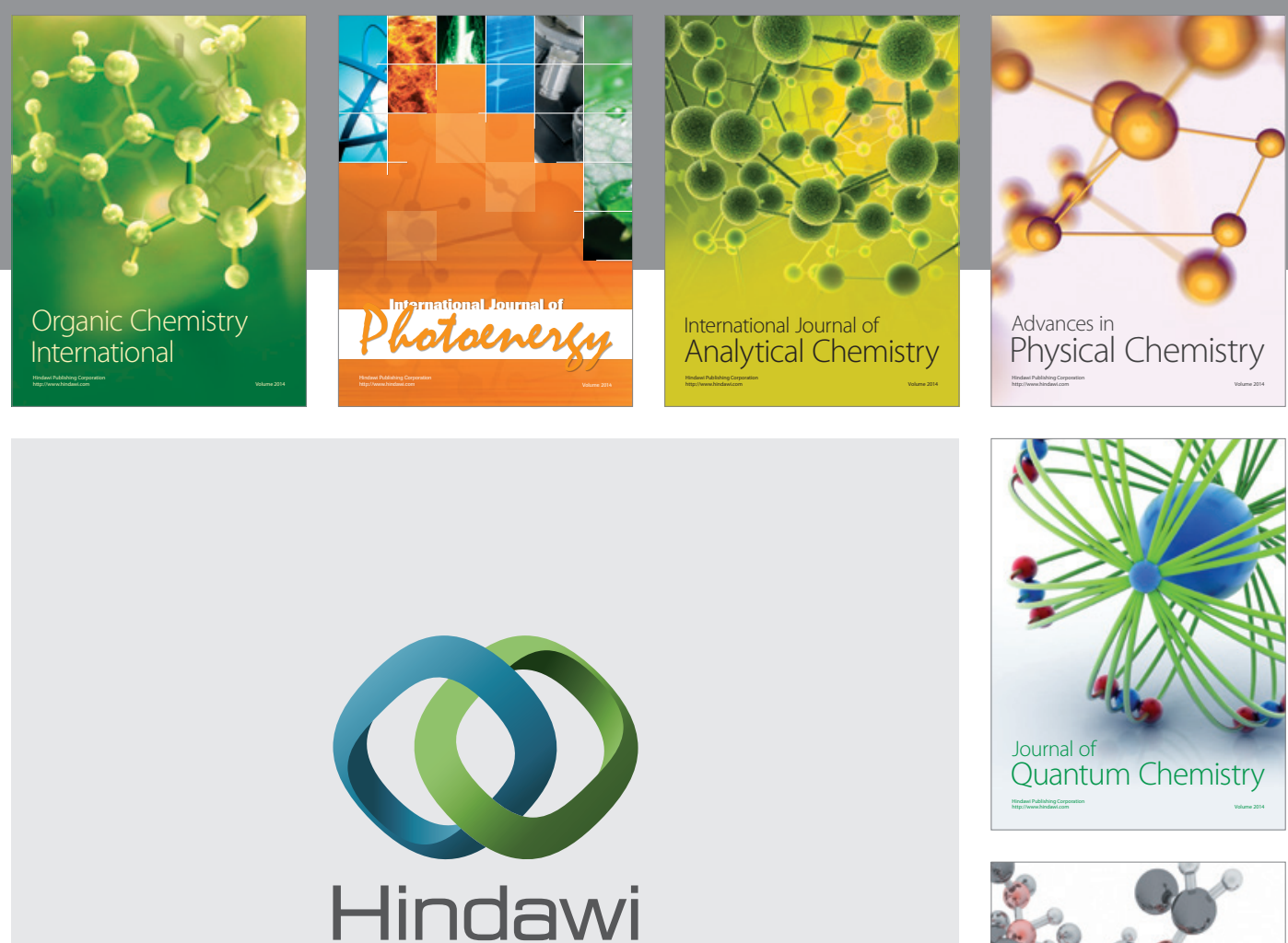

Submit your manuscripts at

http://www.hindawi.com

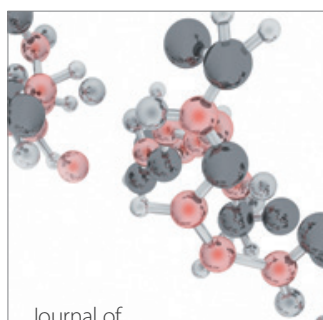

Analytical Methods

in Chemistry

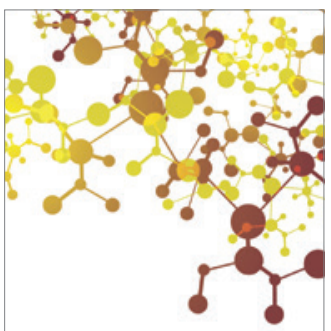

Journal of

Applied Chemistry

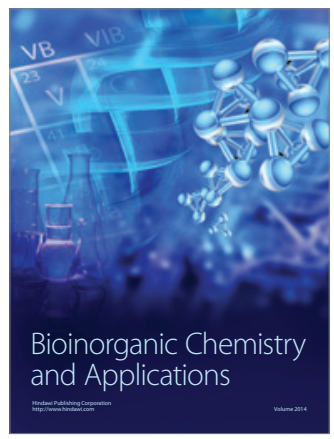

Inorganic Chemistry
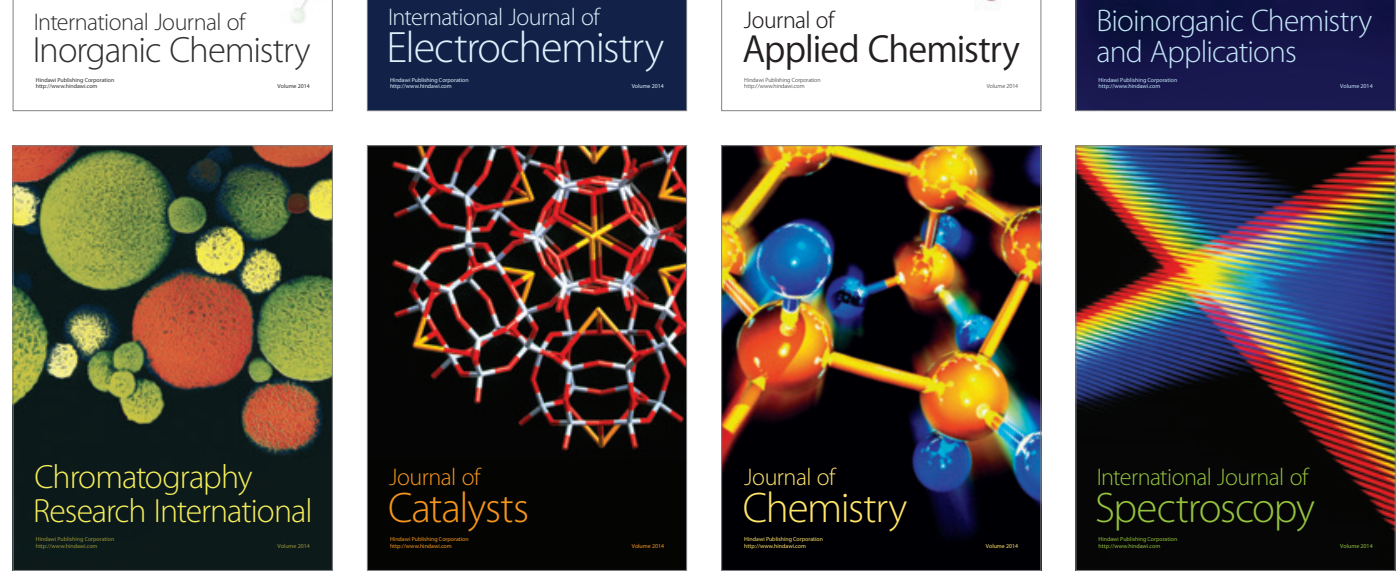